\title{
Using field and nursery treatments to establish Quercus suber seedlings in Mediterranean degraded shrubland
}

\author{
Julio Muñoz-Rengifo ${ }^{(1-2)}$, \\ Esteban Chirino ${ }^{(3)}$, \\ Vicent Cerdán ${ }^{(4)}$, \\ Jesús Martínez ${ }^{(4)}$, \\ Osvaldo Fosado ${ }^{(5)}$, \\ Alberto Vilagrosa ${ }^{(6)}$
}

\begin{abstract}
Cork oak (Quercus suber L.) is a suitable species for restoring Mediterranean ecosystems due to its capacity to resprout after wildfires and its economic importance for the use of cork. Several studies have focused on improving the seedling quality and abiotic conditions at the outplanting site to favour the field performance of $Q$. suber, however, most studies have been conducted by independently testing treatments. The aim of this study was to assess the combined effect of three techniques that focused on reforestation success with $Q$. suber in Mediterranean degraded shrubland: (i) a nursery technique to improve root system development, such as the use of deep containers to develop a longer tap root, combined with two field techniques such as (ii) the use of tree shelters to diminish solar radiation stress, and (iii) shrubland treatments to reduce competition for soil water and nutrients. For this purpose, 1-yearold $Q$. suber seedlings were grown in two containers types: a shallow container (CCS-18) and a deep container (CCL-30). Seedlings were established in a degraded shrubland at three experimental sites in the Calderona mountain range of Castellón, Spain. A factorial design was combined based on container type (CCS-18 and CCL-30), shrubland management (undisturbed shrubland and cleared shrubland in strips) and tree shelters (vegetable fibre tree shelters and no tree shelters). After 2 years of monitoring, the outplanting results indicated that using: (i) a deep container produced a longer taproot, but did not favour better survival or better field performance of seedlings; (ii) tree shelters improved the microweather conditions around seedlings, particularly by reducing excess incoming solar radiation; (iii) cleared shrubland strips reduced competition for soil water by favouring a higher water potential, better maximum photochemical PSII efficiency and higher survival rates for the seedlings established into cleared sites. The results indicate that the cleared shrubland treatment effects overlap the effects of using deep containers and tree shelters. This, in turn, reveals that shrubland clearing is the most suitable technique for favouring the introduction of a resprouter species like $Q$. suber into ecosystems characterized by predominantly degraded shrublands.
\end{abstract}

Keywords: Deep Container, Tree Shelters, Cleared Shrubland, Ecological Restoration

\section{Introduction}

Different biotic and abiotic factors constrain the success of reforestation projects in dry and semiarid degraded areas (Vallejo et al. 2012, Oliet et al. 2015). Stress conditions due to both intense solar radiation, and water and nutrient deficits in introduced seedlings, is one of the main factors to affect the success of forest restoration projects in dry ecosystems (Cortina et al. 2009). Previous studies have analyzed several treatments aimed at reducing these stressful conditions during site outplanting. Some of these treatments have focused on improving root system structure and growth to increase water uptake and to avoid water stress (Chirino et al. 2008, Mariotti et al. 2015b). Other studies have reduced incoming solar radiation stress (Bellot et al. 2002) or competition with coexisting vegetation by shrubland management techniques (Pérez-Devesa et al. 2008, Bashan \& Bar-Massada 2017). However, in most studied cases, the different reforesta- tion techniques followed to improve seedling introduction into degraded shrubland have been analyzed individually and have not been combined.

In Spain, species of the Quercus genus are very important for the forest restoration of Mediterranean ecosystems. Cork oak (Quercus suber L.) is a very interesting typical resprouter Mediterranean species for restoring fire-prone ecosystems (Leite et al. 2018). Like other Quercus species, cork oak develops a long taproot during early development in the nursery (Chirino et al. 2005, Pemán et al. 2006). Therefore, using shallow containers and low volumes physically limits its root system growth (Domínguez et al. 2006, Puértolas et al. 2010). Moreover, field conditions impose other limitations for seedlings to be established in the countryside. Tree shelters have been used to improve microclimatic conditions and protect against herbivory in outplanted seedlings (Puértolas et al. 2010, Defaa et al. 2015, Mariotti et al. 2015a). Photo- 
synthetic photon flux density, air temperature and relative humidity are climate variables that are affected by the use of tree shelters (Devine \& Harrington 2008). Previous studies have shown that tree shelters help improving seedling survival and growth (Vallejo et al. 2006, Andrews et al. 2010). Tree shelter design (height, ventilation and the materials used) determines the protective effect on seedlings (Bellot et al. 2002, Puértolas et al. 2010, García 2016). For this reason, the use of tree shelters built according to an unusual design of vegetable fibres was considered herein.

Degraded ecosystems are characterized by shrubland vegetation dominated by seeder species that well tolerate drought conditions and have a high degree of competitive characteristics (Pausas \& Keeley 2014). Under these conditions, shrubland management techniques to reduce the competitiveness of standing vegetation have been recommended in some studies (Pérez-Devesa et al. 2008), but the selected shrubland management technique (i.e., type, extension and width of clearing strips) must be carefully designed (Madrigal et al. 2014). The use of cleared shrubland strips in parallel with contour curves is a recommended technique for preventing soil erosion and facilitating the outplanting performance of seedlings. This technique is applied to strips no wider than a few metres. It is a selective treatment that helps to conserve juvenile or adult individuals of important species in cleared strips, thereby favouring wildlife feeding and sheltering (Serrada et al. 2005, Masso et al. 2015).

In this context, we hypothesize that the combined effects of several nursery and field techniques, all of which focus on reducing abiotic stress, would better improve the field performance of seedlings in restoration projects compared to each technique individually applied. To test this hypothesis, the objective of this study was to assess the combined effects of using deep containers for nursery culture, tree shelters and cleared shrubland strips with Quercus suber seedlings in early outplanting stages. For this purpose, the following effect were studied: (i) deep containers during nursery culture on seedling morphological characteristics; (ii) vegetable fibre tree shelters to improve the microclimatic conditions around seedlings and diminish solar radiation stress; (iii) cleared shrub- lands strips to reduce competition for soil water between the introduced seedlings and the co-existing vegetation in restoration areas.

\section{Material and Methods}

\section{Study area and experimental sites}

The experimental sites are located in the Calderona mountain range in Castellón, Spain, where altitude ranges between 576 and $727 \mathrm{~m}$ a.s.l., with predominantly westfacing slopes between $13-40 \%$. Sandy soils have developed from rock acidic sandstone. The climate is dry subhumid thermoMediterranean, with an average annual rainfall of $485 \mathrm{~mm}$ and an average temperature of $15.2{ }^{\circ} \mathrm{C}$ (Segorbe HS weather station, data 1961-1990 - Pérez Cueva 1994). The dominant vegetation is degraded shrubland composed mainly of Cistus monspeliensis L., Cistus salviifolius L., and Ulex parviflorus Pourr. At the less degraded sites, individuals of Quercus coccifera L., Rhamnus alaternus L., Pistacia lentiscus L., and Arbutus unedo L. are also present. On the tree layer, some isolated individuals of Pinus halepensis M., and Quercus suber L., can be found. The herbaceous layer is dominated by Brachypodium retusum (Pers.) Beauv. In this study area, the three experimental sites were Puntal de la Bella, El Sapo and Tristán, which presented different geographical localizations, altitudes and west-facing slopes (Tab. 1).

\section{Experiment design}

In order to assess the combined effect of several techniques that focus on reducing abiotic stress in outplanting, a three-factor experimental design was implemented whose factors were: container type $\left(\mathrm{CT}_{f}\right)$, shrubland management $\left(\mathrm{Sm}_{\mathrm{f}}\right)$ and tree shelters $\left(T_{f}\right)$.

Factor container type $\left(\mathrm{CT}_{\mathrm{f}}\right)$ : a CCS-18 container (shallow container: $18 \mathrm{~cm}$ deep; volume of $353 \mathrm{~cm}^{3}$ ) and a CCL-30 container (deep container: $30 \mathrm{~cm}$ deep; volume of $589 \mathrm{~cm}^{3}$ ). Both employed container types were made of high-density polyethylene were cylindrically shaped and open-bottomed, and had a $5 \mathrm{~cm}$ diameter and a cultivation density of 318 seedlings $\mathrm{m}^{-2}$ (Fig. S1 in Supplementary material). The shallow container represented the container widely used for culture in nurseries of the genus Quercus and other Mediterranean species,

Tab. 1 - Geographical coordinates, altitude, slope and slope-facing of the experimental sites.

\begin{tabular}{llll}
\hline \multirow{2}{*}{ Variable } & \multicolumn{3}{c}{ Experimental sites } \\
\cline { 2 - 4 } & $\begin{array}{l}\text { Puntal } \\
\text { de la Bella }\end{array}$ & El Sapo & Tristán \\
\hline Latitude & $39^{\circ} 41^{\prime} \mathrm{N}$ & $39^{\circ} 43^{\prime} \mathrm{N}$ & $39^{\circ} 44^{\prime} \mathrm{N}$ \\
\hline Longitude & $00^{\circ} 23^{\prime} \mathrm{W}$ & $00^{\circ} 27^{\prime} \mathrm{W}$ & $00^{\circ} 28^{\prime} \mathrm{W}$ \\
\hline Altitude (m a.s.l.) & 576 & 722 & 727 \\
\hline Slope (\%) & 13 & 40 & 20 \\
\hline Slope-facing & $270^{\circ} \mathrm{W}$ & $340^{\circ} \mathrm{NW}$ & $210^{\circ} \mathrm{SW}$ \\
\hline
\end{tabular}

while the deep container represented a technological innovation (Chirino et al. 2008). Both containers were manufactured by CETAP-Antonio Matos Lda. (Forestry Containers Manufacturer Company, Espinho, Portugal) and the CCL-30 deep container is patented by this company (Ref. no. 9976, Boletim Propiedade Industrial no. 11-2004, Portugal).

Factor tree shelters $\left(T_{f}\right)$ : vegetable fibre tree shelters (VFT). A panel of vegetable fibre was composed of wicker branches (Salix purpurea), $0.50 \mathrm{~m}$ wide and $1.00 \mathrm{~m}$ long. Wicker branches (length: $1.00 \mathrm{~m}$; diameter: $0.3-0.8 \mathrm{~cm}$ ) were woven with a wire at four height levels $(20,40,60$ and 80 $\mathrm{cm}$ ) to guarantee a stable structure. To build tree shelters, the vegetable fibre panel was placed in an upright position, whose ends were joined to form a cylinder (20 cm diameter, $1.00 \mathrm{~m}$ high). A bamboo cane (height: $1.00 \mathrm{~m}$, diameter: $\sim 1.2 \mathrm{~cm}$ ) was needed to close the panel and form a cylinder to provide vertical support. In the field, tree shelters were buried in soil at a depth of $10-15 \mathrm{~cm}$, along with three other bamboo canes, to confer tree shelters more stability and to avoid the flag effect (Fig. S2, Supplementary material). The opposite experimental treatment was to not use tree shelters (NVFT).

Factor shrubland management $\left(\mathrm{SM}_{\mathrm{f}}\right)$ : cleared shrubland strips (CSs), $3 \mathrm{~m}$ wide, were made running perpendicularly to the hillside's main slope. CSs were alternated with undisturbed shrubland strips (USs), 5 $\mathrm{m}$ wide (Fig. S3, Supplementary material). The clearing of strips at the experimental sites was done with a STIHL FS410 C-E ${ }^{\oplus}$ brush cutter (Andreas Stihl Ltd., Stihl House, Surrey, UK) using bush knives and grinding. At each site, four 3-metre wide strips of CSs and four 5-metre strips of USs were prepared. In USs, a 1-metre diameter circle was cleared to plant Q. suber seedlings.

In each strip (USs and CSs), the other experimental treatments were performed according to the three-factor design. Twelve planting holes $(60 \times 60 \times 60 \mathrm{~cm})$ were made every $3 \mathrm{~m}$ on the centre line of each strip. Holes were made with the help of a pneumatic hammer. No soil was removed from holes to avoid inverting soil horizons. Ninety-six one-year old Quercus suber $L$. seedlings (12 seedlings $\times 2$ container types $\times 2$ shrubland management treatments $\times 2$ tree shelters type as treatment) were planted at each experimental site in January 2011. Thus at each site, there were 48 seedlings per level of container type factor, 24 seedlings per level of shrubland management factor and 24 seedlings per level of tree shelters factor. Twelve seedlings were used to analyze the interactions between factors.

\section{Plant material and nursery culture}

Cork oak (Quercus suber L.) seedlings were grown for a 1-year period in two container types: CCS-18 and CCL-30. Cultivation 
was carried out at the Centro de Investigación y Experimentación Forestal (CIEF) in Quart de Poblet (Valencia, Spain - $39^{\circ} 28^{\prime}$ $\mathrm{N}, 00^{\circ} 31^{\prime} \mathrm{W} ; 70 \mathrm{~m}$ a.s.l), with a mean annual rainfall of $462 \mathrm{~mm}$ and a mean annual temperature of $16.9{ }^{\circ} \mathrm{C}$ (Pérez Cueva 1994). The cork oak acorns from the Calderona mountain range were supplied by the Regional Government Forest Service (Banc de Llavors, Quart de Poblet) and were seeded in January 2010. The substrate was a mixture of limed peat $(60 \%)$ and coconut peat (40\%). A slow-release fertilizer (Plantacote plus $^{\circledast}$, N-P-K: 14-8-14; approaches longevity of 12 months at a mean temperature of 21 ${ }^{\circ} \mathrm{C}$ ) was mixed with the substrate at a substrate dose of $1 \mathrm{~g} \mathrm{~L}^{-1}$. The watering regime was weekly ( 2 days week ${ }^{-1}$ ), with $15 \mathrm{~mm}$ applied in autumn, winter and spring, and 25 $\mathrm{mm}$ in summer.

\section{Seedling morphology and biomass}

At the end of nursery culture after 12 months of cultivation, morphological characterization was carried out. Fifteen seedlings per treatment were randomly sampled, and stem height and basal diameter were measured. Seedlings were cut at the cotyledon insertion point and separated into four fractions: leaves, stem, fine roots (diameter < $2 \mathrm{~mm}$ ) and taproot (diameter > $2 \mathrm{~mm}$ ). The dry weight of each fraction was determined after oven drying at $65{ }^{\circ} \mathrm{C}$ for 48 h. Shoot dry weight $\left(D W_{s}\right)$, root dry weight $\left(D W_{R}\right)$, seedling dry weight $\left(S M_{T}\right)$ were calculated. Two morphological indices were also calculated: root/shoot ratio $\left(D W_{\mathrm{R}} / D W_{\mathrm{S}}\right)$ and root weight ratio $\left(D W_{\mathrm{R}} /\right.$ $\left.S M_{\mathrm{T}}\right)$.

Vegetable fibre tree shelters: inside and outside environmental conditions

In order to compare the environmental conditions inside and outside the vegetable fibre tree shelters (VFT), three climatic variables were monitored. In one set in the nursery, one $\mathrm{Ho8}-032-08 \mathrm{HOBO}^{\circ}$ sensor with a data-logger (Onset Computer Corporation, USA) was placed inside three VFT to measure air temperature $\left(T^{a},{ }^{\circ} \mathrm{C}\right)$ and relative humidity $(R H, \%)$. Photosynthetic

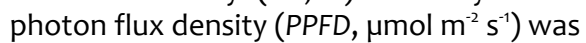
measured using a $\mathrm{Ha}$-Li $\mathrm{HOBO}^{\circ}$ sensor (Onset Computer Corporation, USA). Simultaneously under open site conditions, the same variables $\left(T^{a}, R H\right.$ and PPFD) were measured by similar sensors. Vapour pressure deficit (VPD, $\mathrm{kPa}$ ) was determined from $T^{a}$ and $H R$. These measurements were taken in the nursery in August 2010 on 7 sunny days.

\section{Rainfall, air temperature and relative humidity in the study area}

The outplanting period lasted 2 years: 2011, the wetter year with an annual rainfall of $528.5 \mathrm{~mm}$, a mean air temperature of $16.0{ }^{\circ} \mathrm{C}$ and $68.8 \%$ relative humidity (CEAMET data, the weather station in Alturas, Castellón). April (105.4 mm), March (101.2 $\mathrm{mm}$ ) and November (85.7 mm) were the wettest months, while August ( $4 \mathrm{~mm}$ ) was the driest month (Fig. S4, Supplementary material). In summer, accumulated rainfall came to $49.8 \mathrm{~mm}$. There were 16 rainfall events, for which more than $5 \mathrm{~mm}$ were recorded (minimum: $7.9 \mathrm{~mm}$ and maximum: $11.7 \mathrm{~mm}$ ). However, 2012 was a less rainy year $(397.8 \mathrm{~mm})$ given the $25 \%$ drop compared to the annual rainfall of 2011 , and the $18 \%$ drop compared with the region's average annual $(485 \mathrm{~mm})$. The average temperature was $16.1{ }^{\circ} \mathrm{C}$, while relative humidity was $62.2 \%$. February (0.2 $\mathrm{mm})$, May $(0.8 \mathrm{~mm})$, December $(2.5 \mathrm{~mm})$, August $(4.2 \mathrm{~mm})$ and July $(5.0 \mathrm{~mm})$ were the least rainy months, when rainfall did not exceed $5 \mathrm{~mm}$ month $^{-1}$. The wettest month was October $(172.8 \mathrm{~mm}$ - Fig. S4, Supplementary material) due to extraordinary rainfall $(84.5 \mathrm{~mm})$. The summer of 2012 was very dry $(14 \mathrm{~mm})$. Although 10 rainy events were reported, none exceeded $4 \mathrm{~mm}$. Consequently, there were 120 days (June 21 to September 20) with no significant rainfall (>5 mm).

\section{Seedling performance}

Seedling survival and growth in stem height $\left(H_{s}\right)$ and basal diameter $(D)$ at the experimental sites were measured for $100 \%$ individuals in the experimental plots in January 2011 after plantation, and in June and November 2011 and 2012. The relative growth rate (RGR) was calculated by the differences in the average stem height $\left(H_{s}\right)$ and basal diameter $(D)$ of seedlings between the last measurement $\left(t_{2}\right)$ and the first measurement $\left(t_{1}\right)$ using $R G R=\left[\ln \left(H_{s}\right.\right.$ $\left.\left.t_{2}\right)-\ln \left(H_{s} t_{1}\right)\right] /\left(t_{2}-t_{1}\right)$. To determine the effect of the experimental treatments on seedling water stress, soil moisture and several ecophysiology variables were measured during the first outplanting year (2011). One part of the measures was taken at the end of spring (June), and coincided with the high soil water content conditions (low water stress). The others were taken in summer (August) and coincided with the period with the lowest soil water content conditions (maximum water stress). Five seedlings per experimental treatment and site were randomly selected for this purpose. In each seedling, the following were measured: (1) water potential at midday $\left(\Psi_{\mathrm{md}},-\mathrm{MPa}\right)$ using a Sholander pressure chamber (Soil Moisture $3005^{\oplus}$, Soil moisture Equipment Corp., Santa Barbara, CA, USA); (2) leaf chlorophyll content (LCC, no units) with SPAD $502^{\circledR}$ (Spectrum Technology, Inc. Aurora, USA); (3) maximum quantum yield of Photosystem II (PSII; Fv/Fm under dark conditions) at predawn $\left(\mathrm{Fv} / \mathrm{Fm}_{\mathrm{pd}}\right)$ and midday $\left(\mathrm{Fv} / \mathrm{Fm}_{\mathrm{md}}\right)$ by a fluorimeter PAM $2100^{\circledR}$ (Heinz Walz GmbH, Germany). Simultaneously, soil water content (SWC, \%) at a $15-$ to $20-\mathrm{cm}$ depth was measured in all the selected seedlings for ecophysiological measurements. For this purpose, an EC-5 probe and an instant reader Procheck (both manufactured by Decagon Devices, Inc., USA) were used. The intention was to assess the effect of the experimental treatments shrubland management (CSs and USs) and tree shelters (VFT and NVFT) on the climate variables. Air temperature $\left(T^{a}\right.$, $\left.{ }^{\circ} \mathrm{C}\right)$, relative humidity $(\mathrm{RH}, \%)$ and photosynthetic photon flux density (PPFD, $\mu \mathrm{mol} \mathrm{\textrm {m } ^ { - 2 }}$ $\mathrm{s}^{-1}$ ) were monitored in both CSs and USs, and in the seedlings with VFT and without vegetable fibre tree shelters (NVFT). For these measures, $\mathrm{HOBO}^{\circ}$ sensors (Onset Computer Corporation, USA) model Ho8032-08, with a datalogger for $T^{a}$ and $H R$, and Ha-Li for the PPFD measurements, were used.

\section{Statistical analyses}

The statistical analysis was carried out with the $\mathrm{SPSS}^{\circ}$ statistical software, v. 21.0 (SPSS Inc. Chicago, Illinois, USA). The data on the seedling morphological characteristics at the end of the nursery culture were compared by a $t$-test, when the variables fulfilled theoretical assumptions. A nonparametric test ( $W$ by Wilcoxon) was run for the variables that did not match theoretical assumptions. To test the environmental conditions ( $T^{a}, R H, V P D$, and PPFD) inside and outside the vegetable fibre tree shelters (VFT), an analysis of variance (oneway ANOVA, Tukey's HSD post-hoc test) was carried out. The comparison of the $T^{a}$, $R H, V P D$, and PPFD data in the field was made by a two-factor ANOVA (Tukey's HSD post-hoc test) using shrubland management $\left(\mathrm{SM}_{f}\right)$ and tree shelters $\left(\mathrm{T}_{f}\right)$ as fixed factors. The data of relative growth ratio in stem height $\left(H_{\mathrm{s}}-R G R\right)$ and basal diameter (D-RGR), soil water content (SWC), water potential at midday $\left(\Psi_{\mathrm{md}}\right)$, leaf chlorophyll content (LCC) and maximum quantum yield of Photosystem II $\left(\mathrm{Fv} / \mathrm{Fm}_{\mathrm{pd}}\right.$ and $\left.\mathrm{Fv} / \mathrm{Fm}_{\mathrm{md}}\right)$ were compared by a GLM univariate (three-way ANOVA, Tukey's HSD post-hoc test) at each site to analyze the effect of the experimental factors: container type $\left(\mathrm{CT}_{\mathrm{f}}\right)$, shrubland management $\left(\mathrm{Sm}_{\mathrm{f}}\right)$, and tree shelters $\left(T_{f}\right)$. Data were transformed whenever necessary to assure the assumptions of the ANOVA. The seedling survival data were analyzed by the Kaplan-Meier test (Log Rank-Mantel-Cox) to each experimental factor.

\section{Results}

\section{Morphological characteristics of seedlings}

The analysis of the morphological characteristics of seedlings at the end of the culture period in the nursery indicated several differences between seedlings (Tab. 2). The seedlings grown in the deep CCL-30 container presented higher stem height ( $p$ $=0.009)$, longer taproot $(p<0.001)$, higher shoot dry weight $(p=0.016)$ and seedling dry weight $(p=0.019-$ Tab. 2$)$ values than the seedlings grown in CCS-18. Two tendencies were observed. The seedlings in CCL30 tended to present higher taproot dry weight (root $>2 \mathrm{~mm} ; \mathrm{p}=0.081$ ) and root dry weight ( $p=0.076-$ Tab. 2$)$ values than 
Tab. 2 - Seedling morphological characteristics (mean \pm standard error) at the end of the nursery culture. The results of $t$-test or Wilcoxon test for differences between container types are reported, along with their statistical significance. (DW $)_{s}$ : Shoot dry weight; $\left(D W_{R}\right)$ : root dry weight; $\left(S M_{T}\right)$ : seedling dry weight; $\left(^{* * *}\right): p<0.001 ;(* *): p<0.01 ;\left(^{*}\right): p<0.05 ;$ (ns): non-significant.

\begin{tabular}{|c|c|c|c|c|c|}
\hline \multirow{2}{*}{ Variables } & \multirow{2}{*}{ Units } & \multicolumn{2}{|c|}{ Container types } & \multirow{2}{*}{ Test applied } & \multirow{2}{*}{ Significance } \\
\hline & & CCS-18 & CCL-30 & & \\
\hline Stem height & $\mathrm{cm}$ & $51.26 \pm 3.60$ & $66.46 \pm 4.91$ & W by Wilcoxon & $170.0^{* *}$ \\
\hline Root collar diameter & $\mathrm{mm}$ & $6.70 \pm 0.37$ & $7.47 \pm 0.48$ & W by Wilcoxon & $194.0^{\mathrm{ns}}$ \\
\hline Taproot length & $\mathrm{cm}$ & $17.28 \pm 0.14$ & $29.01 \pm 0.22$ & W by Wilcoxon & $120.0^{* * *}$ \\
\hline Taproot dry weight (>2 mm) & g & $4.28 \pm 0.51$ & $5.95 \pm 0.70$ & $t$-test & $-1.811^{\text {ns }(1)}$ \\
\hline Shoot dry weight & g & $7.69 \pm 0.94$ & $12.66 \pm 1.65$ & W by Wilcoxon & $175.0 *$ \\
\hline Root dry weight & $\mathrm{g}$ & $4.73 \pm 0.53$ & $6.51 \pm 0.81$ & $t$-test & $-1.843^{\text {ns }(1)}$ \\
\hline Seedling dry weight & g & $12.42 \pm 1.37$ & $19.18 \pm 2.41$ & W by Wilcoxon & 176.0 * \\
\hline$D W_{R} / D W_{S}$ ratio & $\mathrm{g} \mathrm{g}^{-1}$ & $0.64 \pm 0.05$ & $0.56 \pm 0.04$ & W by Wilcoxon & $202.0^{\mathrm{ns}}$ \\
\hline$D W_{R} / S M_{T}$ ratio & $\mathrm{g} \mathrm{g}^{-1}$ & $0.38 \pm 0.02$ & $0.35 \pm 0.02$ & $t$-test & $1.290^{\mathrm{ns}}$ \\
\hline
\end{tabular}

Fig. 1 - Seedling survival by the combined effect of the three experimental treatments. (Css): cleared shrubland strips; (USs): undisturbed shrubland strips; (VFT): vegetable fibre tree shelters; (NVFT): without vegetable fibre tree shelters; (CCS-18): shallow container; (CCL30): deep container.

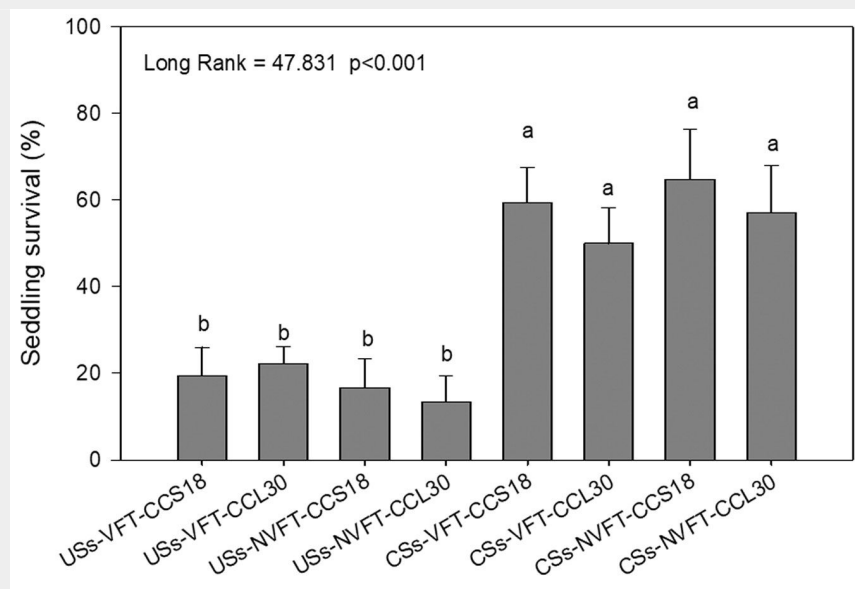

Experimental treatments
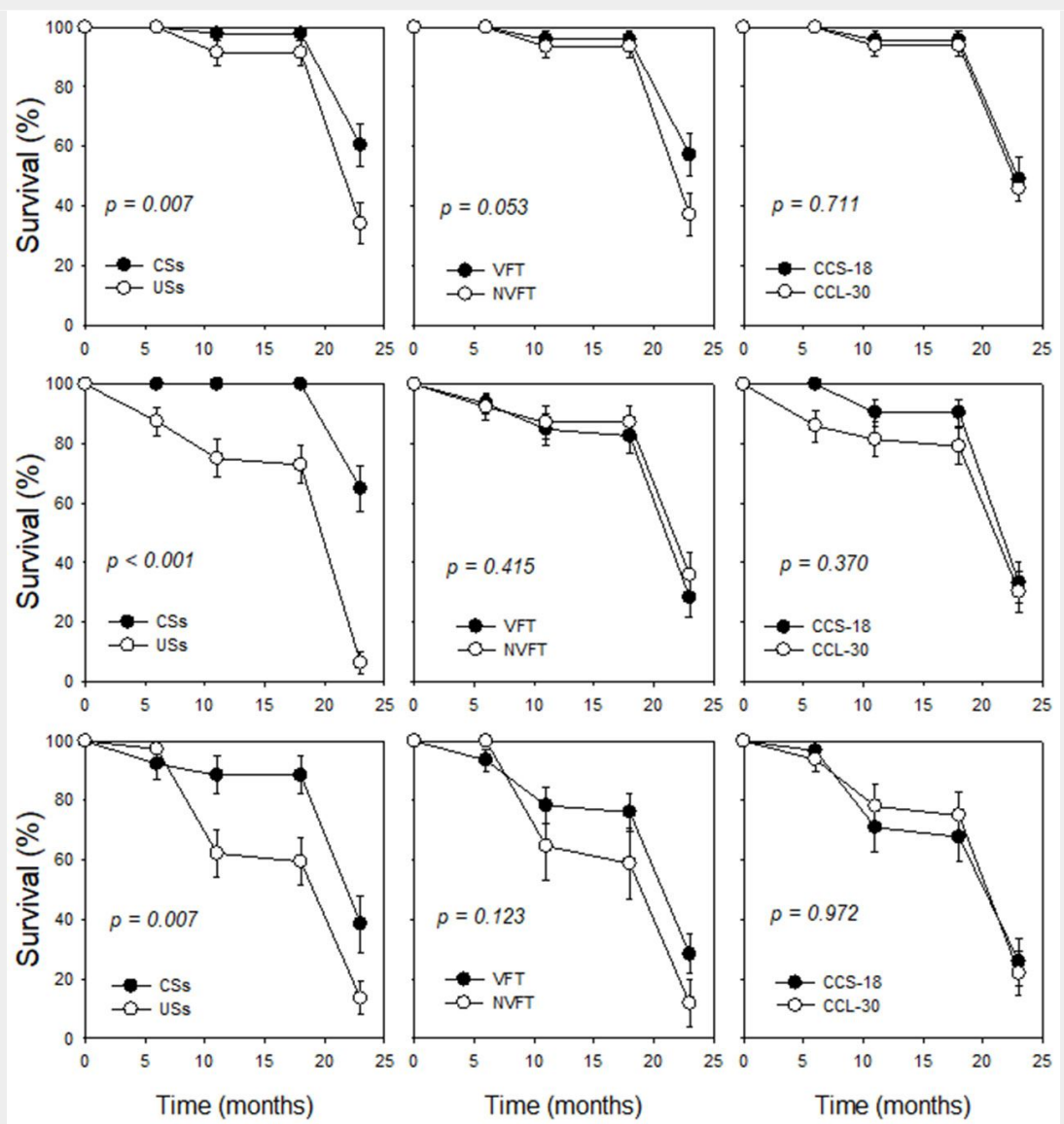

those grown in CCS-18. No significant differences between container types were found for the remaining analyzed morphological variables ( $p>0.05-$ Tab. 2 ).

\section{Seedling survival and post-outplanting growth}

The seedlings in the cleared shrubland strips (CSs), combined with vegetable fibre tree shelter (VFT) or without VFT (NVFT), and in container CCS-18 or CCL-30, maintained the highest survival values (Long Rank = 47.831; $p<0.001-$ Fig. 1), with survival values ranging between $50-59 \%$. A second analysis was run to consider only field treatments (i.e., shrubland management and use of tree shelters). It confirmed that CSs was the main treatment (Long Rank =
Fig. 2 - Seedling survival by the experimental factors at each site. The results are shown per experimental site: Puntal de la Bella (above), El Sapo (middle) and Tristán (below). Data at 6, 11, 18 and 23 months after planting (mean \pm standard error). Kaplan Meier test results (Log Rank, p-value). Abbreviations: cleared shrubland strips (CSs); undisturbed shrubland strips (USs); vegetable fibre tree shelters (VFT); without vegetable fiber tree shelters (NVFT); shallow container (CCS-18); deep container (CCL30). 
Tab. 3 - Relative growth ratio $(R G R)$ in stem height $\left(H_{s}\right)$ and root collar diameter $(D)$ of outplanted seedlings. Results per experimental site of the GLM univariate, three-way ANOVA. Factors: shrubland management $\left(\mathrm{SM}_{f}\right)$, tree shelters $\left(\mathrm{T}_{f}\right)$, and container type $\left(\mathrm{CT}_{f}\right)$. Mean \pm SE, effect of the main factors and interactions between factors (F value). $\left({ }^{* * *}\right): p<0.001 ;(* *): p<0.01 ;\left({ }^{*}\right): p<0.05 ;(n s)$ : non-significant.

\begin{tabular}{|c|c|c|c|c|c|c|c|}
\hline \multirow{2}{*}{ Factors } & \multirow{2}{*}{$\begin{array}{l}\text { Levels/ } \\
\text { F values }\end{array}$} & \multicolumn{2}{|c|}{ Puntal de la Bella } & \multicolumn{2}{|l|}{ El Sapo } & \multicolumn{2}{|l|}{ Tristán } \\
\hline & & H-RGR & D-RGR & H-RGR & D-RGR & H-RGR & D-RGR \\
\hline \multirow{3}{*}{$\begin{array}{l}\text { Shrubland } \\
\text { management } \\
\left(\mathrm{SM}_{\mathrm{f}}\right)\end{array}$} & CSs & $0.057 \pm 0.001$ & $0.013 \pm 0.001$ & $0.035 \pm 0.001$ & $0.110 \pm 0.002$ & $0.010 \pm 0.002$ & $0.010 \pm 0.03$ \\
\hline & USs & $0.073 \pm 0.001$ & $0.007 \pm 0.001$ & $0.085 \pm 0.001$ & $0.005 \pm 0.003$ & $0.007 \pm 0.002$ & $0.005 \pm 0.001$ \\
\hline & $\mathrm{F}$ value & $1.177^{\mathrm{ns}}$ & $13.486 * * *$ & $7.349 * *$ & $3.591^{(1)}$ & $0.732^{\mathrm{ns}}$ & $1.607^{\mathrm{ns}}$ \\
\hline \multirow{3}{*}{$\begin{array}{l}\text { Tree shelters } \\
\left(T_{f}\right)\end{array}$} & VFT & $0.084 \pm 0.001$ & $0.008 \pm 0.001$ & $0.006 \pm 0.001$ & $0.006 \pm 0.001$ & $0.009 \pm 0.002$ & $0.007 \pm 0.002$ \\
\hline & NVFT & $0.046 \pm 0.001$ & $0.012 \pm 0.001$ & $0.003 \pm 0.001$ & $0.010 \pm 0.004$ & $0.006 \pm 0.001$ & $0.010 \pm 0.003$ \\
\hline & $\mathrm{F}$ value & $6.267^{*}$ & $5.275^{*}$ & $0.820^{\mathrm{ns}}$ & $1.727^{\mathrm{ns}}$ & 0.403 & $1.111^{\mathrm{ns}}$ \\
\hline \multirow{3}{*}{$\begin{array}{l}\text { Container type } \\
\left(\mathrm{CT}_{\mathrm{f}}\right)\end{array}$} & CCS-18 & $0.072 \pm 0.001$ & $0.009 \pm 0.002$ & $0.007 \pm 0.001$ & $0.007 \pm 0.002$ & $0.008 \pm 0.002$ & $0.009 \pm 0.002$ \\
\hline & CCL-30 & $0.059 \pm 0.001$ & $0.011 \pm 0.001$ & $0.005 \pm 0.001$ & $0.009 \pm 0.002$ & $0.009 \pm 0.002$ & $0.006 \pm 0.002$ \\
\hline & $\mathrm{F}$ value & $0.740^{\mathrm{ns}}$ & $0.797^{\mathrm{ns}}$ & $0.590^{\mathrm{ns}}$ & $0.116^{\mathrm{ns}}$ & $0.008^{\mathrm{ns}}$ & $0.265^{\mathrm{ns}}$ \\
\hline \multirow{4}{*}{$\begin{array}{l}\text { Interactions } \\
\text { among } \\
\text { treatments }\end{array}$} & $S M_{f} \times T_{f}$ & $0.003^{\mathrm{ns}}$ & $1.024^{\mathrm{ns}}$ & $8.864^{*}$ & $1.861^{\mathrm{ns}}$ & $0.258^{\mathrm{ns}}$ & $1.228^{\mathrm{ns}}$ \\
\hline & $S M_{f} \times C T_{f}$ & $0.345^{\text {ns }}$ & $1.363^{\mathrm{ns}}$ & 0.265 & $0.108^{\mathrm{ns}}$ & $0.052^{\mathrm{ns}}$ & $0.050^{\mathrm{ns}}$ \\
\hline & $\mathrm{T}_{\mathrm{f}} \times \mathrm{CT}_{\mathrm{f}}$ & $0.034^{\mathrm{ns}}$ & $0.000^{\mathrm{ns}}$ & 1.316 & $0.086^{\mathrm{ns}}$ & $0.021^{\mathrm{ns}}$ & $0.023^{\mathrm{ns}}$ \\
\hline & $S M_{f} \times T_{f} \times C T_{f}$ & $1.112^{\mathrm{ns}}$ & $0.014^{\mathrm{ns}}$ & 0.629 & $2.083^{\mathrm{ns}}$ & $0.211^{\mathrm{ns}}$ & $0.254^{\mathrm{ns}}$ \\
\hline
\end{tabular}

46.391; $\mathrm{p}<0.001$ - Fig. S5, Supplementary material) to affect seedling survival. This analysis demonstrated that using tree shelters did not affect seedling survival. The temporal seedling survival dynamics by the experimental factors at each site ratified that neither factor tree shelters (VFT vs. NVFT), nor factor container (CCS-18 vs. CCL30) affected seedling survival. This analysis reported that, once again, the seedlings grown in CSs maintained the highest survival values ( $p<0.01-$ Fig. 2$)$ at the three experimental sites. The seedlings grown in VFT only reflected a higher survival tendency $(p=0.053)$ at the Puntal de la Bella site. The factor container had no effect on seedling survival (Fig. 2). The differences among years associated with rainfall regimes showed that 2012 was less rainy ( $397.8 \mathrm{~mm})$ than $2011(528.5 \mathrm{~mm})$, but this did not affect the differences between treatments, and the seedlings in CSs maintained the highest survival values (Fig. 2).

The growth response of seedlings to experimental treatments differed per site. The seedlings grown in CSs at Puntal de la Bella presented a higher D-RGR than those grown in USs ( $p<0.001-$ Tab. 3 ). In contrast, the seedlings grown in USs (El Sapo) gave higher $H_{s}-R G R$ values than those grown in CSs $(p<0.01-$ Tab. 3$)$. Regarding $D-R G R$, a tendency $(p<0.1)$ was observed. The seedlings with VFT (Puntal de la Bella) had higher $H_{s}-R G R(p=0.05)$ and lower $D$ $R G R(p<0.05)$ values than those grown without VFT (Tab. 3). The factor container had no effect on the RGR $\left(H_{s}\right.$ and $\left.D\right)$ of seedlings. At Tristán, no treatment affected the RGR of seedlings ( $p>0.05-$ Tab. 3). An interaction between $S M_{f}$ and $T_{f}$ was observed at the El Sapo site in H_RGR. A posterior analysis (one-way ANOVA) indicated that the seedlings grown in CSs had higher $\mathrm{H}_{\mathrm{s}}-R G R$ values than those grown in USs $(F=8.067 ; p=0.006)$. $T_{f}$ did not affect this interaction.
Effects of shrubland management and tree shelters on seedlings' microclimatic conditions in the field

The measurements taken in the nursery indicated that VFT brought about no change in the $T^{a}$ inside tree shelter ( $p>$ 0.05 - Tab. 4), but a significant decrease in $\mathrm{RH}$ (about $7 \%$ ) and a significant drop in PPFD (about 59\% of external sunlight) were observed. VPD significantly increased by $15 \%$ in relation to the external environmental conditions (Tab. 4).

At the experimental sites, shrubland management affected only the PPFD values. The seedlings grown in CSs had higher PPFD values (43\% in June and $25 \%$ in August) than those grown in USs $(p<0.001-$ Tab. 5). The use of tree shelters (VFT) significantly lowered the $\mathrm{RH}$ values $(5.3 \%$ in June and $4.0 \%$ in August) and PPFD (54\% in June and $31 \%$ in August - Tab. 5) in relation to the NVFT treatment. An interaction between $\mathrm{SM}_{f}$ and $\mathrm{T}_{f}$ was observed. A later analysis indicated that the seedlings under treatments CSs+NVFT had higher PPFD values than those subject to the other treatments in both June and August $(p<0.001-$ Tab. 5). In June, USs+VFT had the lowest PPFD values, while CSs+VFT and USs+NVFT gave intermediate results. No significant differences were observed between them. In August, no significant differences in the

Tab. 4 - Comparison in the nursery of the environmental conditions inside and outside the vegetable fibre tree shelters (VFT). Data of air temperature $\left(T^{\mathrm{a}}\right)$, relative humidity $(\mathrm{RH})$ and photosynthetic photon flux density (PPFD). The $t$-test results (mean \pm standard error). $(* * *): p<0.001 ;(n s)$ : non-significant.

\begin{tabular}{llrrr}
\hline Variable & Units & $\begin{array}{c}\text { Outside } \\
\text { VFT }\end{array}$ & \multicolumn{1}{c}{$\begin{array}{c}\text { Inside } \\
\text { VFT }\end{array}$} & \multicolumn{1}{c}{$t$-test } \\
\hline$T^{\mathrm{a}}$ & ${ }^{\circ} \mathrm{C}$ & $26.91 \pm 0.10$ & $27.05 \pm 0.10$ & $-1.050^{\text {ns }}$ \\
\hline$R H$ & $\%$ & $72.61 \pm 0.42$ & $67.88 \pm 0.43$ & $8.752^{* * *}$ \\
\hline$V P D$ & $\mathrm{kPa}$ & $1.10 \pm 0.02$ & $1.32 \pm 0.02$ & $-7.634^{* * *}$ \\
\hline$P P F D$ & $\mu \mathrm{mol} \mathrm{m}^{2} \mathrm{~s}^{-1}$ & $1.07 \pm 0.02$ & $0.44 \pm 0.02$ & $-59.697^{* * *}$ \\
\hline
\end{tabular}

three treatments were noted (CSs+VFT, USs+VFT and Uss+NVFT - Tab. 5).

\section{Soil water content and plant} ecophysiology response

The analysis of the effect of experimental treatments $\left(\mathrm{SM}_{\mathrm{f}}, \mathrm{T}_{f}\right.$ and $\left.\mathrm{CT}_{f}\right)$ on soil water content (SWC), water potential at midday $\left(\Psi_{\mathrm{md}}\right)$, leaf chlorophyll content $(L C C)$, and maximum quantum yield of Photosystem II ( Fv/Fm at predawn and midday) per experimental site gave different results across sites. When spring ended (June 2011), the shrubland management factor had less effect on the analyzed variables. Only at the Tristán site the seedlings grown in CSs had higher SWC that those in USs ( $p=0.036-$ Fig. $3 C$ ), which favoured less stress in the seedlings in CSs ( $\Psi_{\mathrm{md}}, \mathrm{p}=0.015$ - Tab. S1, Supplementary material). A similar tendency $(p<0.1-$ Tab. S1) was observed at the El Sapo site for SWC regarding the shrubland management factor.

All the SWC values were higher than $17 \%$, which did not directly limit seedlings' physiological activity. Under these optimal soil moisture conditions, using vegetable fibre tree shelters or not, was the experimental factor with the stronger effect on water potential and $\mathrm{Fv} / \mathrm{Fm}$ in seedlings. At the Puntal de la Bella site, the seedlings grown with VFT presented lower water stress 
Tab. 5 - Effect of the experimental treatments' shrubland management $\left(\mathrm{SM}_{\mathrm{f}}\right)$ and tree shelters $\left(\mathrm{T}_{f}\right)$ on climatic variables air temperature $\left(T^{a}\right)$, relative humidity $(R H)$, vapour pressure deficit (VPD) and photosynthetic photon flux density (PPFD). Measurements taken in June 2011 (above) and August 2011 (below). Results of the GLM univariate (two-way ANOVA). Factors: shrubland management and tree shelters; F value, Tukey's HSD post hoc test. $\left({ }^{* *}\right): p<0.001 ;(* *): p<0.01 ;(*): p<0.05 ;(n s)$ : non-significant.

\begin{tabular}{|c|c|c|c|c|c|c|}
\hline $\begin{array}{l}\mathrm{Pe}- \\
\text { riod }\end{array}$ & Factors & Param. & $T^{\mathrm{a}}$ & $R H$ & $V P D$ & PPFD \\
\hline \multirow{11}{*}{ 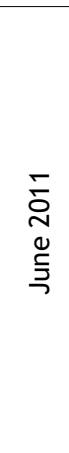 } & \multirow{3}{*}{$\begin{array}{l}\text { Shrubland } \\
\text { management } \\
\left(\mathrm{SM}_{\mathrm{f}}\right)\end{array}$} & CSs & $22.6 \pm 0.2$ & $69.8 \pm 0.6$ & $1.08 \pm 0.03$ & $523.1 \pm 23.3^{\mathrm{a}}$ \\
\hline & & USs & $22.5 \pm 0.2$ & $70.1 \pm 0.6$ & $1.04 \pm 0.02$ & $298.5 \pm 16.7^{b}$ \\
\hline & & F value & $0.37^{\text {ns }}$ & $1.64^{\mathrm{ns}}$ & $0.68^{\mathrm{ns}}$ & $61.35^{* * *}$ \\
\hline & \multirow{3}{*}{$\begin{array}{l}\text { Tree shelters } \\
\left(T_{f}\right)\end{array}$} & VFT & $22.4 \pm 0.1$ & $68.1 \pm 0.6^{b}$ & $1.08 \pm 0.02$ & $258.1 \pm 15.3^{b}$ \\
\hline & & NVFT & $22.6 \pm 0.2$ & $71.9 \pm 0.7^{\mathrm{a}}$ & $1.04 \pm 0.03$ & $563.6 \pm 23.6^{a}$ \\
\hline & & $\mathrm{F}$ value & $0.92^{\text {ns }}$ & $18.48^{* * *}$ & $0.92^{\mathrm{ns}}$ & $118.05^{* * *}$ \\
\hline & & $\mathrm{CSs} \times \mathrm{VFT}$ & $22.3 \pm 0.2$ & $68.2 \pm 0.9$ & $1.07 \pm 0.03$ & $351.9 \pm 25.8^{b}$ \\
\hline & & CSs $\times$ NVFT & $22.9 \pm 0.2$ & $71.4 \pm 1.0$ & $1.10 \pm 0.04$ & $694.4 \pm 36.6^{a}$ \\
\hline & & USs $\times$ VFT & $22.5 \pm 0.2$ & $68.0 \pm 0.8$ & $1.09 \pm 0.03$ & $164.7 \pm 15.0^{c}$ \\
\hline & & USs $\times$ NVFT & $22.4 \pm 0.2$ & $72.3 \pm 0.9$ & $0.99 \pm 0.03$ & $432.8 \pm 28.0^{b}$ \\
\hline & & F value & $3.20^{\mathrm{ns}}$ & $0.52^{\mathrm{ns}}$ & $3.98^{\mathrm{ns}}$ & $64.21^{* * *}$ \\
\hline \multirow{11}{*}{$\begin{array}{l}\underset{丶}{\sigma} \\
\text { on } \\
\stackrel{<}{<}\end{array}$} & \multirow{3}{*}{$\begin{array}{l}\text { Shrubland } \\
\text { management } \\
\left(\mathrm{SM}_{\mathrm{f}}\right)\end{array}$} & CSs & $22.9 \pm 0.2$ & $77.4 \pm 0.9$ & $0.9 \pm 0.04$ & $646.1 \pm 30.1^{\mathrm{a}}$ \\
\hline & & USs & $22.3 \pm 0.3$ & $80.2 \pm 1.0$ & $0.9 \pm 0.05$ & $483.3 \pm 28.9^{b}$ \\
\hline & & F value & $0.38^{\mathrm{ns}}$ & $0.24^{\mathrm{ns}}$ & $1.68^{\mathrm{ns}}$ & $15.25^{* * *}$ \\
\hline & \multirow{3}{*}{$\begin{array}{l}\text { Tree shelters } \\
\left(T_{f}\right)\end{array}$} & VFT & $22.2 \pm 0.3$ & $80.0 \pm 1.1^{a}$ & $0.87 \pm 0.05$ & $461.1 \pm 26.2^{b}$ \\
\hline & & NVFT & $22.9 \pm 0.2$ & $77.6 \pm 0.9^{b}$ & $0.85 \pm 0.04$ & $668.3 \pm 32.0^{\mathrm{a}}$ \\
\hline & & F value & $0.92^{\mathrm{ns}}$ & $10.17^{* *}$ & $0.92^{\mathrm{ns}}$ & $25.12^{* * *}$ \\
\hline & \multirow{5}{*}{$\begin{array}{l}\mathrm{SM}_{\mathrm{f}} \times \mathrm{T}_{\mathrm{f}} \\
\text { interactions }\end{array}$} & $\mathrm{CSs} \times \mathrm{VFT}$ & $22.3 \pm 0.4$ & $80.5 \pm 1.4$ & $0.8 \pm 0.07$ & $472.5 \pm 34.9^{b}$ \\
\hline & & CSs $\times$ NVFT & $23.5 \pm 0.3$ & $74.4 \pm 1.0$ & $0.9 \pm 0.05$ & $819.6 \pm 44.7^{a}$ \\
\hline & & USs $\times$ VFT & $22.1 \pm 0.2$ & $79.6 \pm 1.5$ & $0.9 \pm 0.08$ & $449.7 \pm 39.2^{b}$ \\
\hline & & USs $\times$ NVFT & $22.6 \pm 0.4$ & $80.8 \pm 1.4$ & $0.8 \pm 0.06$ & $517.0 \pm 42.4^{b}$ \\
\hline & & F value & $3.20^{\mathrm{ns}}$ & $0.58^{\mathrm{ns}}$ & $3.98^{\mathrm{ns}}$ & $18.14^{* * *}$ \\
\hline
\end{tabular}
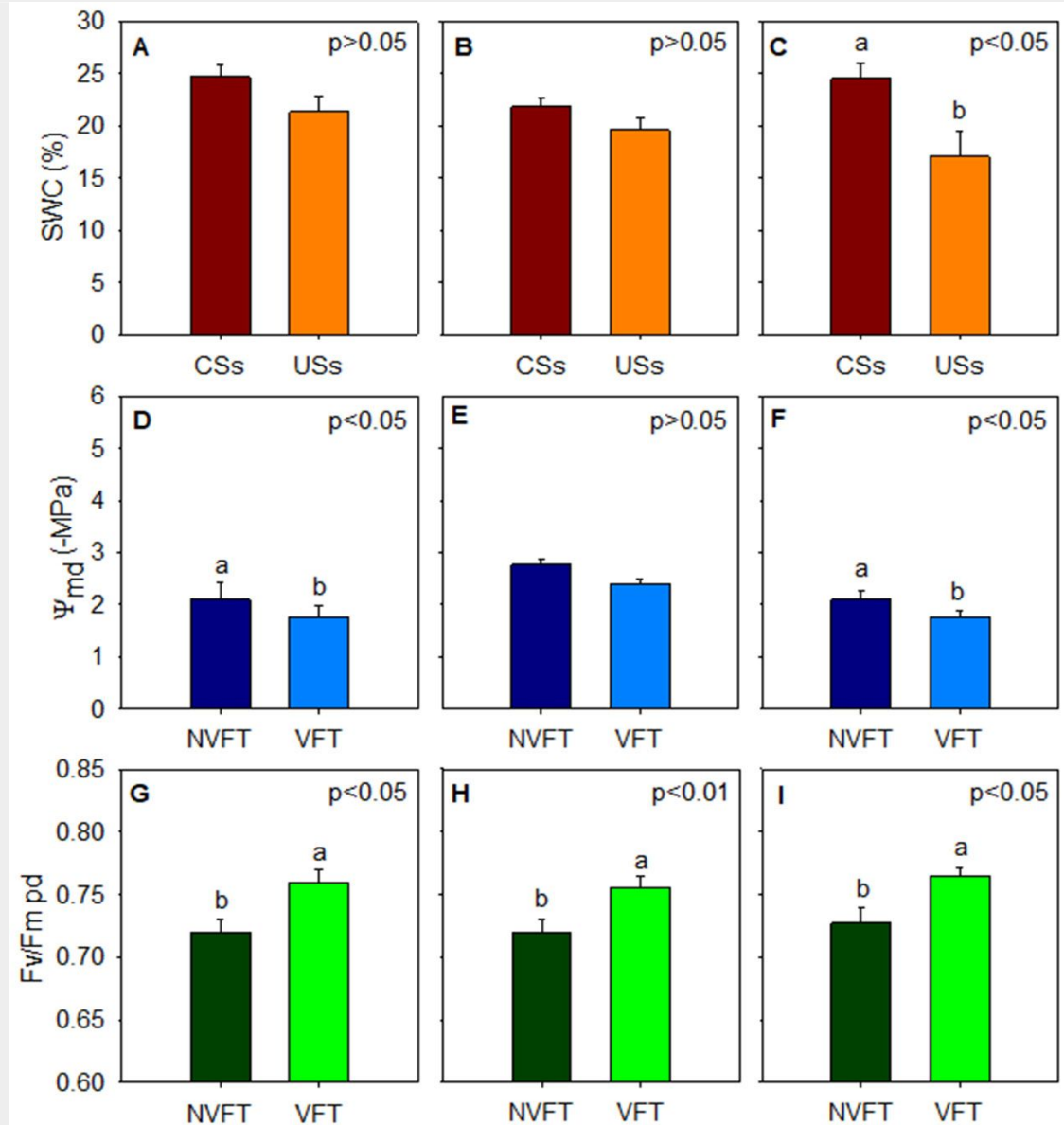

than those in NVFT ( $p=0.016-$ Fig. 3D), expressed as higher $\Psi_{\mathrm{md}}$ values. This result gave higher $\mathrm{Fv} / \mathrm{Fm}_{\mathrm{pd}}$ values ( $\mathrm{p}=0.019$ - Fig. $3 G$ ) in the seedlings with VFT. At the Tristán site, the seedlings with VFT gave higher $\Psi_{\mathrm{md}}$ values $(\mathrm{p}=0.014-\mathrm{Fig} .3 \mathrm{~F})$ and higher $\mathrm{Fv} /$ $\left.F m_{p d} ; p=0.018-F i g .3 l\right)$ than those without VFT. A similar result for $\mathrm{Fv} / \mathrm{Fm}_{\mathrm{pd}}(\mathrm{p}=0.003$ - Fig. $3 \mathrm{H}$ ) was observed at the El Sapo site.

The container type factor $\left(\mathrm{CT}_{f}\right)$ had little effect on the analyzed variables. Only at the Puntal de la Bella did the seedlings cultivated in CCL30 have higher LCC values than those in CCS-18 ( $p=0.041-$ Tab. S1, Supplementary material). Two interactions between factors were observed: an interaction between $\mathrm{SM}_{f}$ and $\mathrm{CT}_{f}$ in LCC ( $\mathrm{p}=$ 0.007 - Tab. S1) at Puntal de la Bella, and another interaction between factors $T_{f} \times$ $\mathrm{CT}_{\mathrm{f}}$ in $\Psi_{\mathrm{md}}(\mathrm{p}=0.049-$ Tab. S1) at Tristán. In both cases, the one-way ANOVA did not find any effects of these factors separately $(p<0.05)$. The results of the GLM univariate three-way ANOVA (factors: tree shelters, container type and shrubland management) are shown in Tab. S1 and Tab. S7 in the Supplementary material.

As expected, at mid-summer the SWC values notably lowered in relation to the June values. However, shrubland management was the factor that most affected the variables analyzed at all the sites. At Puntal de la Bella, the seedlings grown in CSs had higher SWC ( $p=0.010-$ Fig. $4 \mathrm{~A})$ and, consequently, presented less water stress ( $\Psi_{\mathrm{md}} \mathrm{P}$

Fig. 3 - Measurements taken in spring of soil water content (SWC, \%), water potential at midday $\left(\Psi_{\mathrm{md}},-\mathrm{MPa}\right)$, leaf chlorophyll content (LCC, units SPAD), and maximum efficiency of photosystem PSII ( $\mathrm{FV} / \mathrm{Fm})$ at predawn per experimental site. Results of the GLM univariate, three-way ANOVA; factors: tree shelters $\left(\mathrm{T}_{f}\right)$, container type $\left(\mathrm{CT}_{f}\right)$ and shrubland management $\left(\mathrm{SM}_{\mathrm{f}}\right)$. Mean \pm standard error. Values followed by the same letter were not significantly different ( $p>0.05)$. Results shown by experimental sites: Puntal de la Bella (panels A, D and G), El Sapo (panels B, E and $\mathrm{H}$ ) and Tristán (panels $\mathrm{C}, \mathrm{F}$ and I). 
Fig. 4 - Measurements taken in summer of soil water content (SWC, \%), water potential at midday $\left(\Psi_{\mathrm{md}},-\mathrm{MPa}\right)$, and maximum efficiency of photosystem PSII ( $F v / F m)$ at predawn and midday per experimental site. Results of the GLM univariate, three-way ANOVA; factors: tree shelters $\left(T_{f}\right)$, container type $\left(\mathrm{CT}_{f}\right)$ and shrubland management $\left(\mathrm{SM}_{\mathrm{f}}\right)$. Mean \pm standard error. Values followed by the same letter are not significantly different ( $p>0.05)$. Results shown by the experimental site Puntal de la Bella (panels A, D and G), El Sapo (panels B, E and H) and Tristán (panels C, F and I).
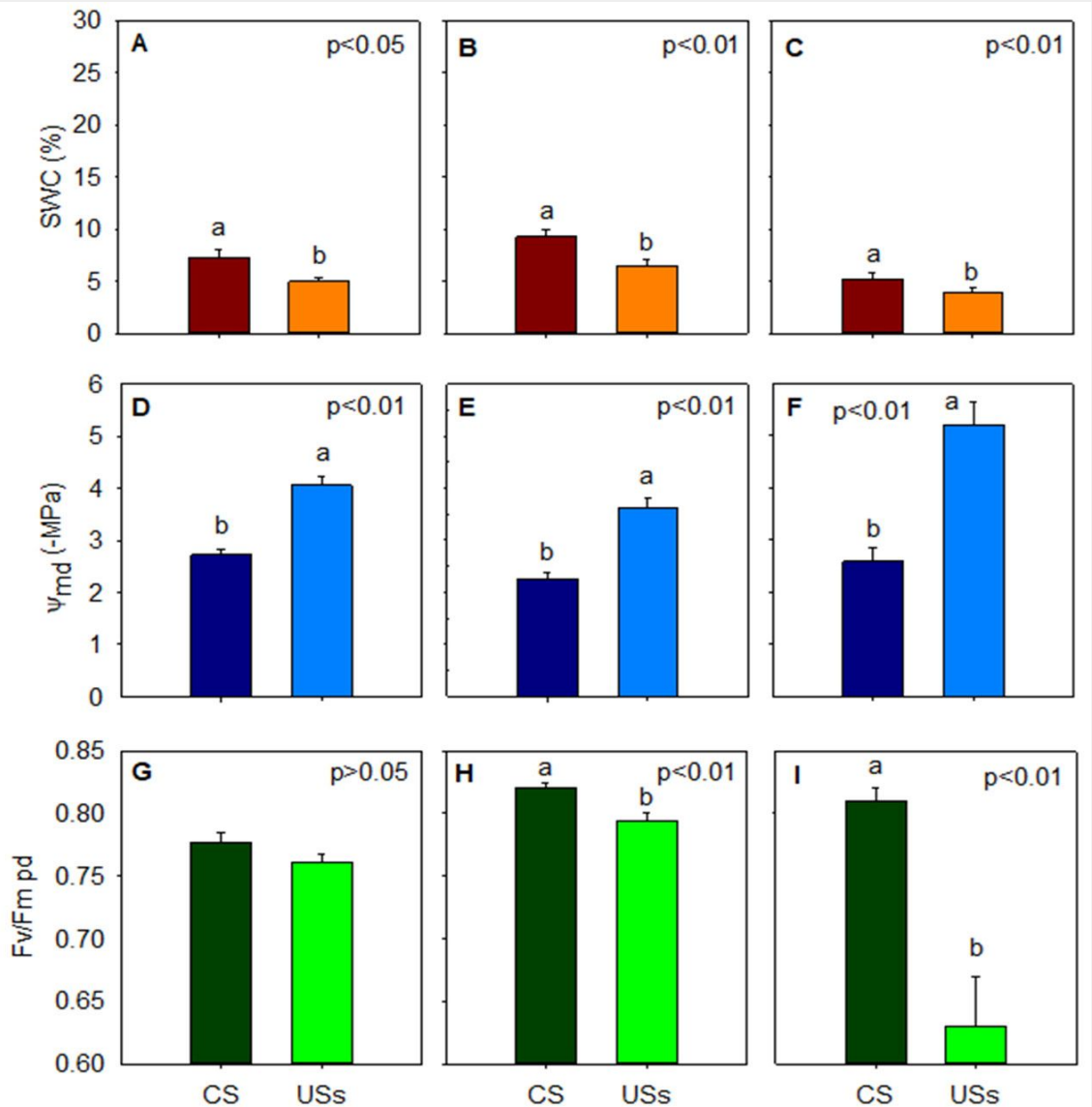

Shrubland management Factor
$=0.001-$ Fig. 4D) and higher Fv/ Fmmd values $(p=0.014-$ Tab. S2, Supplementary material) than those in USs. Similar results were observed at El Sapo site in SWC ( $p<0.01$ - Fig. 4B), $\Psi_{m d}$ ( $p<0.001$ - Fig. 4E), and $\mathrm{Fv} / \mathrm{Fm}$ at predawn ( $\mathrm{p}<0.01-\mathrm{Fig} .4 \mathrm{H})$. At the Tristán site, the seedlings grown in CSs had higher SWC ( $p<0.001$ - Fig. $4 G)$, presented lower water stress $(p<0.001-$ Fig. $4 \mathrm{H}$ ) and higher $\mathrm{Fv} / \mathrm{Fm}$ at both predawn ( $\mathrm{p}<$ 0.001 - Fig. 4l) and midday ( $p<0.001-$ Tab. S2) than the seedlings in USs. At Puntal de la Bella, the seedlings grown in CCL-30 tended to show higher LCC ( $p=0.071-$ Tab. S2) than those grown in CCS-18. At El Sapo, an interaction between $\mathrm{SM}_{f}$ and $\mathrm{T}_{f}$ was observed ( $p=0.008-$ Tab. S2). Oneway ANOVA indicated that the seedlings grown in CSs+VFT had lower LCC values ( $p$ $=0.008$ ) than for the other treatments, and no significant differences appeared among them. Another interaction between factors $\mathrm{SM}_{\mathrm{f}} \times \mathrm{T}_{\mathrm{f}}$ was observed at Tristán ( $\mathrm{p}$ $=0.022-$ Tab. S2). The one-way ANOVA reported that the seedlings in USs had higher LCC $(p=0.043)$ than those in CSs.

\section{Discussion}

Effect of deep container on the morphological characteristics and seedling field performance

The effect of increasing container volume on seedling morphology development is widely documented (Prieto-Ruiz et al.
2007, Gil \& Díaz 2016). However, the effect of increased container depth on seedling morphology may have different responses according to species characteristics (Chirino et al. 2005, Kostopoulou et al. 2011, De la Fuente et al. 2017). In this study, a deep container was used to produce seedlings with a longer taproot and a higher $\mathrm{DW}_{\mathrm{R}} /$ $D W_{\mathrm{S}}$ ratio to favour not only deep root system development, but also the rapid colonization of deeper soil layers before the first summer. At the end of the nursery culture, the seedlings cultivated in a deep container (CCL-30) presented a longer taproot and a tendency to have higher root dry weight values. They also showed longer stem height and higher shoot dry weight values. Consequently, no significant difference in the $D W_{R} / D W_{S}$ ratio was observed (Tab. 2). Previous studies that employed containers with similar depths in Quercus coccifera, Q. ilex (Chirino et al. 2005) and Q. suber (Chirino et al. 2008) reported the production of seedlings with no significant differences in height and basal diameter compared to those grown in standard containers. This also allowed to produce seedlings destined to dry ecosystems with a higher $D W_{R} / D W_{S}$ ratio in the seedlings grown in deep containers (Chirino et al. 2005, 2008, Mariotti et al. 2015b), which favours better root growth and greater resistance to Mediterranean water stress characteristics (Pemán et al. 2006, De la Fuente et al. 2017). Other studies that have employed deep containers produced seedlings with a longer taproot (Trinidad et al. 2015) and a higher stem height (Mariotti et al. 2015c). However, effects on stem height, diameter and other morphological characteristics have not always been observed (Trinidad et al. 2015, De la Fuente et al. 2017).

Relative resources allocation to roots or leaves is considered a key factor in species strategies in relation to the use of water (De la Riva et al. 2014) and seedling survival in the field (Villar-Salvador et al. 2013). In our study, we expected the seedlings grown in CCL-30 to develop a deeper root system over a shorter time period, which would promote higher survival rates, more growth $\left(H_{s}-R G R, D-R G R\right)$ and a better physiological status than the seedlings grown in short CCS-18 containers. Our results did not meet the expected results because using deep containers did not lead to any differences in seedling survival (Fig. 2), growth (Tab. 3) or ecophysiological status (i.e., water potential and maximum quantum yield of Photosystem II - Tab. S1, Tab. S2 in Supplementary material) compared to the seedlings in CCS-18. This result may be due to the fact that both seedling types had a similar $D W_{R} / D W_{S}$ ratio upon planting. Some previous studies have also reported no effects on water status in different container types (Oliet et al. 2012). 
Effect of vegetable fibre tree shelters on microclimatic conditions, seedling survival and growth

The design of tree shelters (height, ventilation and material used to build them) af fects the micro-meteorological conditions inside tree shelters (Bellot et al. 2002, Puértolas et al. 2010, Mechergui et al. 2013). Former studies have shown that using tree shelters in relation to external micro-meteorological conditions increases air temperature (Devine \& Harrington 2008, Pemán et al. 2010, Mechergui \& Pardos 2017). In contrast, the VFT in our study did not increase temperature in relation to the external environmental conditions (Tab. 4). The used material and tree shelter design, i.e., built with small wicker shoots, allowed air to flow through lateral ribs, which favours good ventilation and avoids overheating. These results are consistent with those obtained by Bellot et al. (2002), who used tree shelters made by a network of Stipa tenacissima L. leaves. Tree shelters also reduced the PPFD, which has been widely documented. For example, Bellot et al. (2002) reported a reduction in PPFD of between $70 \%$ and $80 \%$, Jiménez et al. (2005) reported a $78 \%$ reduction, while Devine \& Harrington (2008) indicated one of $15-54 \%$ for radiation at an open site. In our study, VFT reduced PPFD by $59 \%$.

Regarding survival, several studies have indicated that using tree shelters significantly increases seedling survival (Vallejo et al. 2006, Defaa et al. 2015). Although Valkonen (2008) and Oliet et al. (2016) observed only marginal improvement, other authors did not find this relation (Oliet et al. 2012). The use of VFT in our study did not increase seedling survival, although a tendency ( $p=0.053$ - Fig. 2) was observed at Puntal de la Bella. Other studies have indicated that using tree shelters also favours an increased growth height (Defaa et al. 2015, Oliet et al. 2016, Mechergui \& Pardos 2017). We report the effect of tree shelters (VFT) only at the Puntal de la Bella site, where $H_{s}-R G R$ increased and $D-R G R$ lowered (Tab. 3). For the ecophysiological seedling response, the effects of using VFT were observed only in spring, mainly on the $\mathrm{Fv} / \mathrm{Fm}_{\mathrm{pd}}$ values at the three experimental sites. This last result agrees with Puértolas et al. (2010) and Ceacero et al. (2012), who reported that tree shelters improved the physiological characteristics of seedlings. However, other studies like that Pemán et al. (2010) did not find any differences in $\mathrm{FV} / \mathrm{Fm}$ either with or without tree shelters.

\section{Effect of shrubland management on} seedling survival and field performance Studies on the competitive or facilitative effect of some shrub species on seedling survival and field performance have been well-documented (Pérez-Devesa et al. 2008, Rey et al. 2016, Macek et al. 2018, Santana et al. 2018). In summer, under lower SWC conditions, shrubland manage- ment (CSs treatment) was the factor that contributed more to diminish water stress, and gave better maximum quantum yields status of Photosystem II and seedling performance. Our study indicated that the seedlings grown in CSs had higher PPFD (Tab. 5) and also higher SWC (Tab. S1, Supplementary material), which favoured less water stress (expressed as higher $\Psi_{\mathrm{md}}-$ Fig. 4), as well as higher $\mathrm{Fv} / \mathrm{Fm}$ values at both predawn (Fig. 4) and midday (Tab. S1, Tab. S2, Supplementary material). This better water and physiological status probably led to higher seedling survival in CSs than for the seedlings grown in USs. Our results agree with those of Pérez-Devesa et al. (2008), who reported that the seedlings planted in the middle line of CSs presented more soil moisture, their survival was $22 \%$ higher, they displayed better growth for height and root collar diameter, and had higher $\mathrm{Fv} / \mathrm{Fm}$ values at both predawn and midday than those planted in USs (control treatment). However, differences in seedling survival have not always been observed with these treatments (Valdecantos et al. 2009, Herrero-Jáuregui et al. 2016). The seedlings in CSs presented a higher $\mathrm{H}$ $R G R$ at El Sapo, which is consistent with the results reported in Pistacia lentiscus by Valdecantos et al. (2009) for $\mathrm{H}_{\mathrm{s}}-\mathrm{RGR}$, and by Madrigal et al. (2014) in Pinus halepensis growth in Guadalajara, Spain. Another effect of the CSs treatment was its higher PPFD (43\% in June and 25\% in August) than for the seedlings in USs. This result is consistent with Pérez-Devesa et al. (2008), who obtained $30 \%$ higher PPFD, and also coincides with the increased chlorophyll content in Pinus reported by Cambrón-Sandoval et al. (2011). It is very important to indicate that, for our experimental sites, high PPFD values at midday in summer can cause radiation stress for seedlings (Cortina et al. 2009, Granados et al. 2016). The year 2012 was relatively dry (Fig. S4, Supplementary material) as 120 days went by with no significant rainfall $(<5 \mathrm{~mm})$. Thus, mortality of almost $100 \%$ was expected (Vallejo \& Alloza 1998). However, the survival values of the seedlings planted in the CSs remained between $39 \%$ and $64 \%$.

Overall, our study results indicated that in both spring and summer, at the Tristan site the CSs treatment (shrubland management factor) and the use of vegetable fibre tree shelters (tree shelters factor) had a stronger effect on the ecophysiological response of seedlings (Fig. 3, Fig. 4). Tristán was the only site that was SW slope-facing. This slope-facing type presents more solar exposure, higher water stress and more stress by PPDF. Under those most unfavourable conditions compared to the other sites, both the studied treatments contributed to a better seedling water status and to improved seedling performance. We speculate that a better response of both experimental treatments for sites with more unfavourable conditions could be expected.

\section{Conclusions}

According to our starting hypothesis, we expected the combined use of deep containers, vegetable fibre tree shelters and shrubland clearing to improve the field performance of Q. suber seedlings to a greater extent than when applying only one treatment. Our results did not ratify this hypothesis, but highlighted the fact that shrubland clearing was the main treatment to improve $Q$. suber performance. The effects of the cleared shrubland treatment overlapped the functional improvement of deep containers and tree shelters. Using deep containers and tree shelters had no significant effect on seedling survival, despite improvements in microclimatic conditions and differences in the root system developed by seedlings, as observed at the end of the nursery culture. Accordingly, we conclude that shrubland clearing is the most suitable technique to favour the introduction of $Q$. suber into ecosystems where shrublands dominate as a result of degraded forests.

\section{List of abbreviations}

The following abbreviations have been used throughout the text:

- $\mathrm{Ct}_{\mathrm{f}}$ : Factor container type;

- $T_{f}$ : Factor tree shelters;

- VFT: Vegetable fibre tree shelters;

- NVFT: Without vegetable fibre tree shelters:

- $\mathrm{Sm}_{\mathrm{f}}$ : Factor shrubland management;

- CSs: Cleared shrubland strips;

- USs: Undisturbed shrubland strips;

- $T^{a}$ : Air temperature;

- RH: Relative humidity;

- PPFD: Photosynthetic photon flux density;

-VPD: Vapour pressure deficit;

- $H_{s}$ : Stem height;

- D: Basal diameter

- $H_{s}-R G R$ : Relative growth ratio in stem height;

- D-RGR: Relative growth ratio in diameter;

- DW : Shoot dry weight;

- $\mathrm{DW}_{\mathrm{R}}$ : Root dry weight;

- $S M_{\mathrm{T}}$ : Seedling dry weight;

- $D W_{\mathrm{R}} / \mathrm{DW}_{\mathrm{s}}$ : Root/shoot ratio;

- $D W_{\mathrm{R}} / S M_{\mathrm{T}}$ : Root weight ratio;

- $\Psi_{\mathrm{md}}$ : Water potential at midday;

- LCC: Leaf chlorophyll content;

- Fv/Fmpd: Maximum quantum yield of Photosystem II at predawn;

- $\mathrm{Fv} / \mathrm{Fm}_{\mathrm{md}}:$ Maximum quantum yield of Photosystem II at midday;

- SWC: Soil water content.

\section{Author contributions}

$J M-R, E C h, V C, J M$ and $A V$ conceived and designed the experiment. JM-R, ECh, VC and $J M$ performed the experiment and took field measurements. ECh and OF carried out the statistical analysis. JM-R, ECh, AV and OF contributed to the data analysis and data interpretation. JM-R, ECh and AV wrote and edited the manuscript. 


\section{Acknowledgments}

This research was partially funded by the Centro para la Investigación y Experimentación Forestal (CIEF) and by the Fundación Centro de Estudios Ambientales del Mediterráneo (CEAM), both from Comunidad Valenciana (Spain). Author JCMR is grateful to the Instituto de Fomento al Talento Humano (IFTH) of the Government of Ecuador for the fellowship granted for postgraduate studies abroad. AV work was partially funded by Projects CGL-2011-30531-CO2-02 and CGL2015-69773-C2-2-P MINECO/FEDER from the Spanish Government. CEAM is supported by the Generalitat Valenciana and IMAGINA project (PROMETEU/2019/110 - Generalitat Valenciana).

\section{References}

Andrews DM, Barton CD, Czapka SJ, Kolka RK, Sweeney BW (2010). Influence of tree shelters on seedling success in an afforested riparian zone. New Forests 39 (2): 157-167. - doi: 10.1007/ s11056-009-9161-8

Bashan D, Bar-Massada A (2017). Regeneration dynamics of woody vegetation in a Mediterranean landscape under different disturbancebased management treatments. Applied Vegetation Science 20 (1): 106-114. - doi: 10.1111/avsc. 12274

Bellot J, De Urbina JO, Bonet A, Sánchez JR (2002). The effects of tree shelters on the growth of Quercus coccifera L. seedlings in a semiarid environment. Forestry 75 (1): 89-106. doi: 10.1093/forestry/75.1.89

Cambrón-Sandoval VH, España-Boquera ML, Sánchez-Vargas NM, Sáenz-Romero C, VargasHernández JJ, Herrerías-Diego Y (2011). Producción de clorofila en Pinus pseudostrobus en etapas juveniles bajo diferentes ambientes de desarrollo [Chlorophyll production in Pinus pseudostrobus under different development environments]. Revista Chapingo serie Ciencias Forestales y del Ambiente 17 (2): 253-260. - doi: 10.5154/r.rchscfa.2010.09.077

Ceacero CJ, Díaz-Hernández JL, Del Campo AD, Navarro-Cerrillo RM (2012). Interactions between soil gravel content and neighboring vegetation control management in oak seedling establishment success in Mediterranean environments. Forest Ecology and Management 271: 10-18. - doi: 10.1016/j.foreco.2012.01.044 Chirino E, Vilagrosa A, Fernández R, Vallejo R (2005). Uso de contenedor profundo en el cultivo de Quercineas. Efectos sobre el crecimiento y distribución de biomasa [Use of deep container in the cultivation of Quercineas. Effects on growth and biomass distribution]. In: Proceedings of the "IV Congreso Forestal Nacional (SECF)" (Gobierno de Aragón ed). Zaragoza (España) Jun 2005. Imprenta repes, Zaragoza, Spain, pp. 7. [in Spanish]

Chirino E, Vilagrosa A, Hernández E, Matos A, Vallejo $V$ (2008). Effects of a deep container on morpho-functional characteristics and root colonization in Quercus suber L. seedlings for reforestation in Mediterranean climate. Forest Ecology and Management 256: 779-785. - doi: 10.1016/j.foreco.2008.05.035

Cortina J, Pérez-Devesa M, Vilagrosa A, Abourouh $M$, Messaoudène $M$, Berrahmouni $N$,
Neves L, Almeida H, Khaldi A (2009). Field techniques to improve cork oak establishment. In: "Cork Oak Woodlands on the Edge: Ecology, Adaptive Management, and Restoration" (Aronson J, Pereira JS, Pausas JG eds). Society for Ecological Restoration International, Island Press, Washington, USA, pp. 141-150. [online] URL: http://www.researchgate.net/publication/ 313725912

De la Fuente LM, Ovalle JF, Arellano EC, Ginocchio R (2017). Use of alternative containers for promoting deep rooting of native forest species used for dryland restoration: the case of Acacia caven. iForest - Biogeosciences and Forestry 10 (5): 776-782. - doi: 10.3832/ifor2101010

De la Riva EG, Pérez-Ramos I, Fernández CN, Olmo M, Arana TM, Villar R (2014). Rasgos funcionales en el género Quercus: estrategias adquisitivas frente a conservativas en el uso de recursos [Functional traits in the genus Quercus: acquisitive versus conservatives resourceuse-strategies]. Revista Ecosistemas 23 (2): 8289. [in Spanish] [online] URL: http://revistaeco sistemas.net/index.php/ecosistemas/article/vie $\mathrm{w} / 869$

Defaa C, Elantry S, Lahlimi EAS, Achour A, El Mousadik A, Msanda F (2015). Effects of tree shelters on the survival and growth of Argania spinosa seedlings in Mediterranean arid environment. International Journal of Ecology 2015: 1-6. - doi: 10.1155/2015/124075

Devine WD, Harrington CA (2008). Influence of four tree shelter types on microclimate and seedling performance of Oregon white oak and western redcedar. Research Paper PNW-RP576, Pacific Northwest Research Station, USDA Forest Service, Portland, OR, USA, pp. 35. - doi: 10.2737/PNW-RP-576

Domínguez S, Herrero N, Carrasco I, Ocaña I, Peñuelas J, Mexal J (2006). Container characteristics influence Pinus pinea seedlings development in the nursery and field. Forest Ecology and Management 221 (1-3): 63-71. - doi: 10.1016/ j.foreco.2005.08.031

García JP (2016). Lecciones aprendidas y tareas pendientes en la actividad repobladora y viverística [Learned lessons and pending tasks in the afforestation activities and nursery]. In: Proceedings of the " $\mathrm{VI}$ Congreso Forestal Nacional (SECF) Montes: Servicios y desarrollo rural" (Sociedad Española de Ciencias Forestales ed). Vitoria-Gasteiz (Spain) 10-14 June 2013. SECF, Spain, vol. 39, pp. 177-195. [in Spanish]

Gil Al, Díaz LJ (2016). Evaluación de tipos de contenedores sobre el crecimiento radical de café (Coffea arabica L. cv. Castillo) en etapa de vivero. [Assessment of containers types on the coffee radical growth (Coffea arabica L. cv. (astillo) in nursery stage]. Revista Colombiana de Ciencias Hortícolas 10 (1): 125-136. [in Spanish]

Granados ME, Vilagrosa A, Chirino E, Vallejo VR (2016). Reforestation with resprouter species to increase diversity and resilience in Mediterranean pine forests. Forest Ecology and Management 362: 231-240. - doi: 10.1016/j.foreco.20 15.12.020

Herrero-Jáuregui C, Schmitz MF, Pineda FD (2016). Effects of different clipping intensities on above-and below-ground production in sim- ulated herbaceous plant communities. Plant Biosystems 150 (3): 468-476. - doi: 10.1080/112 63504.2014.965800

Jiménez MN, Navarro FB, Ripoll MA, Bocio I, De Simón E (2005). Effect of shelter tubes on establishment and growth of Juniperus thurifera L. (Cupressaceae) seedlings in Mediterranean semi-arid environment. Annals of Forest Science 62 (7): 717-725. - doi: 10.1051/forest:2005 062

Kostopoulou P, Radoglou K, Dini-Papanastasi OD, Adamidou C (2011). Effect of mini-plug container depth on root and shoot growth of four forest tree species during early developmental stages. Turkish Journal of Agriculture and Forestry 35 (4): 379-390. [online] URL: http:// journals.tubitak.gov.tr/agriculture/abstract.htm ?id $=11841$

Leite C, Oliveira V, Lauw A, Pereira H (2018). Effect of a drought on cork growth along the production cycle. In: "Theory and Practice of Climate Adaptation" (Alves F, Leal FW, Azeiteiro $U$ eds). Climate Change Management, Springer, Cham, Switzerland, pp. 127-136. - doi: 10.1007/ 978-3-319-72874-2_7

Macek P, Schöb C, Núñez-Avila M, Hernández IR, Pugnaire Fl, Armesto JJ (2018). Shrub facilitation drives tree establishment in a semiarid fogdependent ecosystem. Applied Vegetation Science 21 (1): 113-120. - doi: 10.1111/avsc.12301

Madrigal J, Hernando C, Guijarro M, Vega JA (2014). Distribución de biomasa en las copas y el matorral tras clareos mecanizados intensos de regenerado post-incendio de Pinus pinaster Ait.: implicaciones para la prevención de incendios de copa. [Biomass distribution in the canopy and scrubland after mechanized intense clearing of post-fire regeneration of $\mathrm{Pi}$ nus pinaster Ait: implications for prevention cup fires]. Cuadernos de la Sociedad Española de Ciencias Forestales 40: 123-130. [in Spanish] Mariotti B, Maltoni A, Jacobs DF, Tani A (2015a). Tree shelters affect shoot and root system growth and structure in Quercus robur during regeneration establishment. European Journal of Forest Research 134 (4): 641-652. - doi: 10.1007/s10342-015-0878-y

Mariotti B, Maltoni A, Chiarabaglio PM, Giorcelli A, Jacobs DF, Tognetti R, Tani A (2015b). Can the use of large, alternative nursery containers aid in field establishment of Juglans regia and Quercus robur seedlings? New Forests 46 (5-6): 773-794. - doi: 10.1007/s11056-015-9505-5

Mariotti B, Maltoni A, Jacobs DF, Tani A (2015c). Container effects on growth and biomass allocation in Quercus robur and Juglans regia seedlings. Scandinavian Journal of Forest Research 30 (5): 401-415. - doi: 10.1080/02827581.2015.102 3352

Masso S, Mesléard F, Dutoit T (2015). Using shrub clearing, draining, and herbivory to control bramble invasion in Mediterranean dry grasslands. Environmental Management 56 (4): 933-945. - doi: 10.1007/s00267-015-0541-x Mechergui T, Pardos M (2017). Impacts of mulching and tree shelters on Cork oak (Quercus suber L.) seedling survival and growth after four growing seasons. Revue d'Écologie 72 (4): 410-424. [online] URL: http://hdl.handle.net/20 $42 / 62683$

Mechergui T, Pardos M, Boussaidi N, Hasnaoui B, 
Jacobs DF (2013). Development of cork oak (Quercus suber L.) seedlings in response to tree shelters and mulching in northwestern Tunisia. Journal of Forestry Research 24 (2): 193-204. doi: 10.1007/s11676-013-0345-x

Oliet JA, Artero F, Cuadros S, Puértolas J, Luna L, Grau JM (2012). Deep planting with shelters improves performance of different stocktype sizes under arid Mediterranean conditions. New Forests 43 (5-6): 925-939. - doi: 10.1007/ s11056-012-9345-5

Oliet JA, Vasquez de Castro A, Puértolas J (2015). Establishing Quercus ilex under Mediterranean dry conditions: sowing recalcitrant acorns versus planting seedlings at different depths and tube shelter light transmissions. New Forests 46 (5-6): 869-883. - doi: 10.1007/s11056-015-94 95-3

Oliet JA, Planelles R, Artero F, Domingo-Santos JM (2016). Establishing Acacia salicina under dry Mediterranean conditions: the effects of nursery fertilization and tree shelters on a mid-term experiment with saline irrigation. Ciencia e Investigación Agraria 43 (1): 69-84.

Pausas JG, Keeley JE (2014). Abrupt climate-independent fire regime changes. Ecosystems 17 (6): 1109-1120. - doi: 10.1007/s10021-014-9773-5

Pemán J, Peguero-Pina JJ, Valladares F, Gil-Pelegrín E (2010). Evaluation of unventilated tree shelters in the context of Mediterranean climate: insights from a study on Quercus faginea seedlings assessed with a $3 \mathrm{D}$ architectural plant model. Ecological Engineering 36 (4): 517-526. doi: 10.1016/j.ecoleng.2009.11.021

Pemán J, Voltas J, Gil-Pelegrín E (2006). Morphological and functional variability in the root system of Quercus ilex L. subject to confinement: consequences for afforestation. Annals of Forest Science 63 (4): 425-430. - doi: 10.1051/forest: 2006022

Pérez Cueva AJ (1994). Atlas Climático de la Comunidad Valenciana, 1961-1990 [Climate Atlas of Valencian Community, 1961-1990]. Conselleria de Obras Públicas, Urbanismo y Transportes, Generalitat Valenciana, Valencia, Spain, pp. 205. [in Spanish]

Pérez-Devesa $M$, Cortina J, Vilagrosa A, Vallejo $R$ (2008). Shrubland management to promote Quercus suber L. establishment. Forest Ecology and Management 255 (3): 374-382. - doi: 10.1016 /j.foreco.2007.09.074

Prieto-Ruiz JA, Domínguez-Calleros PA, CornejoOviedo EH, Návar-Cháidez JD (2007). Efecto del envase y del riego en vivero en el establec- imiento de Pinus cooperi Blanco en dos condiciones de sitio [Effect of container and irrigation in nursery in Pinus cooperi Blanco establishment under two site conditions]. Madera y Bosques 13 (1): 79-97. [in Spanish] - doi: 10.21829/ myb.2007.1311237

Puértolas J, Oliet JA, Jacobs DF, Benito LF, Peñuelas JL (2010). Is light the key factor for success of tube shelters in forest restoration plantings under Mediterranean climates? Forest Ecology and Management 260 (5): 610-617. doi: 10.1016/j.foreco.2010.05.017

Rey PJ, Alcántara JM, Manzaneda AJ, SánchezLafuente AM (2016). Facilitation contributes to Mediterranean woody plant diversity but does not shape the diversity-productivity relationship along aridity gradients. New Phytologist 211 (2): 464-476. - doi: 10.1111/nph.13916

Santana VM, Baeza MJ, Valdecantos A, Vallejo VR (2018). Redirecting fire-prone Mediterranean ecosystems toward more resilient and less flammable communities. Journal of Environmental Management 215: 108-115. - doi: 10.1016/j.jenvman.2018.03.063

Serrada R, Navarro CR, Pemán J (2005). La calidad de las repoblaciones forestales: una aproximación desde la selvicultura y la ecofisiología [The afforestation quality: an approach from forestry and ecophysiology]. Investigación Agraria - Sistemas y Recursos Forestales 14 (3):462-481. [in Spanish] - doi: 10.5424/srf/2005 143-00943

Trinidad O, Vargas J, Aldrete A, López J, Fierros A (2015). Sustratos y tamaños de contenedor en el desarrollo de Hevea brasiliensis Müll. Arg. en vivero [Substrates and container sizes in the development of Hevea brasiliensis Müll. Arg. in nursery]. Revista Mexicana de Ciencias Forestales 6 (31): 94-113. [in Spanish] - doi: 10.2929 8/rmcf.v6i31.199

Valdecantos A, Baeza MJ, Vallejo VR (2009). Vegetation management for promoting ecosystem resilience in fire-prone Mediterranean shrublands. Restoration Ecology 17 (3): 414-421. - doi: 10.1111/j.1526-100X.2008.00401.x

Valkonen S (2008). Survival and growth of planted and seeded oak (Quercus robur L.) seedlings with and without shelters on field afforestation sites in Finland. Forest Ecology and Management 255 (3-4): 1085-1094. - doi: 10.1016 /j.foreco.2007.10.038

Vallejo VR, Alloza JA (1998). The restoration of burned lands: the case of eastern Spain. Large Forest Fires 1998: 91-108.
Vallejo V, Aronson J, Pausas J, Cortina J (2006). Restoration of Mediterranean woodlands. Restoration ecology. The New Frontier 14: 193207. [online] URL: http://books.google.com/ books?id=egA4gFNRq7sC

Vallejo VR, Smanis A, Chirino E, Fuentes D, Valdecantos A, Vilagrosa A (2012). Perspectives in dryland restoration: approaches for climate change adaptation. New forests 43 (5-6): 561579. - doi: 10.1007/s11056-012-9325-9

Villar-Salvador P, Nicolás J, Heredia N, Uscola M (2013). Quercus ilex L. In: "Producción y Manejo de Semillas y Plantas Forestales" (Pemán J, Navarro-Cerrillo RM, Nicolás JL, Prada MA, Serrada $\mathrm{R}$ eds). Tomo II, Organismo Autónomo Parques Nacionales, Serie Forestal, Ministerio de Agricultura, Alimentación y Medio Ambiente, Madrid, Spain, pp. 226-250. [in Spanish]

\section{Supplementary Material}

Fig. S1 - Details of the used containers.

Fig. S2 - Panel of vegetable fiber composed per wicker branch (Salix purpurea).

Fig. S3 - View of a cleared shrubland strips (CSs) and undisturbed shrubland strips (USs) on both sides.

Fig. S4 - Ombroclimatic diagram. Monthly mean rainfall and temperature.

Fig. S5 - Seedling survival by the combined effect of the two experimental treatments.

Tab. S1 - Measures taken in June 2011 of soil water content (SWC, \%), water potential at midday $\left(\Psi_{\mathrm{md}},-\mathrm{MPa}\right)$, leaf chlorophyll content (LCC, units SPAD), and maximum efficiency of photosystem PSII ( $F v / F m$ at predawn and midday) per experimental site.

Tab. S2 - Measures taken in August 2011 of soil water content (SWC, \%), water potential at midday $\left(\Psi_{\mathrm{md}},-\mathrm{MPa}\right)$, leaf chlorophyll content (LCC, units SPAD), and maximum efficiency of photosystem PSII ( $\mathrm{Fv} / \mathrm{Fm}$ at predawn and midday) per experimental site.

Link: Munoz-Rengifo_3095@supplo01.pdf 